\title{
Ethanol effects on self-administration of alfentanil, cocaine, and nomifensine in rhesus monkeys
}

Received: 24 April 1996 / Final version: 7 November 1996

\begin{abstract}
A common form of polydrug use is that of cocaine and ethanol. The identification of an ethanol-cocaine combination product, cocaethylene, with properties in common with cocaine, has led to speculation that this metabolite may contribute to the co-abuse of cocaine and ethanol. In order to determine whether ethanol pretreatments selectively altered cocaine's reinforcing potency, ethanol pretreatments were given to monkeys trained to press levers and receive IV infusions of several doses of cocaine or alfentanil. In addition, nomifensine, a drug which has a mechanism of action similar to cocaine's, was evaluated in the presence and absence of ethanol in monkeys with the cocaine baseline history. Ethanol, in doses ranging from 100 to $1780 \mathrm{mg} / \mathrm{kg}$, given $10 \mathrm{~min}$ before the 130-min session, had no effect on responding maintained by alfentanil. These doses also had no significant effect on cocaine-maintained responding, although the potency of cocaine as a reinforcer was increased following administration of $1000 \mathrm{mg} / \mathrm{kg}$ ethanol in two of the four subjects. The potency of nomifensine as a reinforcer was significantly increased by $1000 \mathrm{mg} / \mathrm{kg}$ ethanol, but again, this enhancement was limited to the same two subjects. These data indicate that, in this paradigm, cocaethylene did not selectively modify cocaine's reinforcing potency, but there appear to be individual differences with respect to ethanol's ability to stimulate rates of drug-maintained responding.
\end{abstract}

This work was supported by USPHS grant DA 04403. Animals used in these studies were maintained in accordance with the University Committee on Use and Care of Animals, University of Michigan, and guidelines of the Committee on Care and use of Laboratory Animal Resources, National Research Council (Department of Health, Education and Welfare, Publication No. (NIH)

J.M. Aspen

Department of Psychology, University of Chicago,

Chicago, Illinois, USA

G. Winger (

Department of Pharmacology,

University of Michigan Medical School, 1301 MSRB III,

Ann Arbor, MI 48109-0626, USA
Key words Ethanol $\cdot$ Cocaine $\cdot$ Nomifensine Alfentanil · Cocaethylene · Drug self-administration · Rhesus monkeys

\section{Introduction}

The concurrent use of ethanol and cocaine appears to be widespread among cocaine users, with estimates of the number of cocaine users who also consume ethanol ranging from 50-90\% (Weiss et al. 1988; Grant and Harford 1990). In addition, more cocaine users are ultimately diagnosed as alcoholics than any other subgroup of drug users (Rounsaville et al. 1991). One explanation offered for this pattern of polydrug use is that ethanol is consumed during cocaine binges in order to counteract the hyperexcitability, nervousness, and insomnia which arise with cocaine use (Siegel 1984). An additional explanation is that there is a metabolic interaction between ethanol and cocaine such that an additional compound is formed that maintains this polydrug abuse (Jatlow 1993).

The presence of such a compound, a cocaine ethyl ester known as cocaethylene, has been detected in the urine of individuals who have administered both cocaine and ethanol (Rafla and Epstein 1979; Smith 1984). Cocaethylene has also been found in the post-mortem plasma samples of individuals who had used both ethanol and cocaine (Jatlow et al. 1991), and in the blood samples of individuals admitted to the emergency room for cocaine overdose (Bailey 1993). Clinical research has shown that cocaethylene formation is induced in humans by administering cocaine and ethanol in succession (McCanceKatz et al. 1993).

Self-administration studies in rhesus monkeys show cocaethylene to be equal or slightly more potent than cocaine as a reinforcer (Jatlow et al. 1991). Cocaethylene has been shown to produce cocaine-like interoceptive effects in rats and squirrel monkeys, although it was three to five times less potent than cocaine in studies of drug discrimination (Woodward et al. 1991; Katz et al. 1992). Although less potent in producing increases in locomotor 
activity, cocaethylene appears to be equipotent to cocaine in producing convulsant effects, and more potent in producing lethal effects in mice (Katz 1992). The increased reinforcing potency of cocaethylene, as well as a decrease in the locomotor effects or "jitteriness" which many users find bothersome, may make consumption of ethanol and cocaine preferable to cocaine alone. However, the increased toxicity of cocaethylene makes such polydrug use an even greater concern. The toxic effects of cocaine and ethanol may be more dangerous than the additive effects of the two drugs if their interaction forms an even more lethal metabolite.

Fowler et al. (1992) found that ingestion of ethanol did not influence the pharmacokinetics of cocaine itself, and that cocaethylene synthesis was too slow to account for acute behavioral effects and toxicity. It is unclear how the concurrent ingestion of ethanol influences cocaine use, and whether drug users actually ingest more cocaine in the presence of ethanol.

The purpose of the present study was to determine whether prior administration of ethanol would modify rates of behavior maintained by cocaine. The specific question was whether ethanol administration would result in an apparent increase in the potency of cocaine, as would be expected if production of cocaethylene increased the apparent duration of cocaine action. In order to determine whether any interaction between ethanol and cocaine was specific to cocaine, two other drugs that serve as reinforcers in this preparation were examined following ethanol administration. One drug, nomifensine, is a dopamine reuptake blocker that has a similar potency and effectiveness to cocaine as a reinforcer in rhesus monkeys (Winger and Woods 1985). The other, alfentanil, also maintains high rates of responding in this preparation, but does so by action on the mu opioid receptor (Winger 1994).

\section{Materials and methods}

\section{Subjects}

Subjects were three male and four female rhesus monkeys individually housed in $83.3 \times 76.2 \times 91.4 \mathrm{~cm}$ stainless steel cages. Two female (RC245 and 671P) and two male (RC177 and J30) monkeys participated in the cocaine-nomifensine aspect of the study, and an additional three monkeys (one male and two females) participated in the alfentanil aspect of the study. Each of the monkeys had several months of experience with the baseline drug, and had received other pretreatment drugs, such as dopamine or opioid antagonists, during their history. The animals ranged in weight from 4.8 to $8.7 \mathrm{~kg}$, and were fed 15-20 protein enriched monkey chows (PMI Feeds, St Louis, Mo., USA) twice daily, and supplemented with fresh fruit.

\section{Apparatus}

Intravenous silicone catheters were surgically implanted in each monkey using ketamine $(10 \mathrm{mg} / \mathrm{kg}$ IM) and either pentobarbital $(15 \mathrm{mg} / \mathrm{kg} \mathrm{IV})$ or xylazine $(2 \mathrm{mg} / \mathrm{kg} \mathrm{IM})$ as anesthetics. The catheter was placed in either a jugular, brachial, or femoral vein, depending on the surgical history of each monkey, and passed subcu- taneously to the mid-scapular region where it exited the body. The catheter then traveled through a hollow steel restraining arm to the outside of the cage, where it was joined to additional silicone tubing which passed through a roller infusion pump (Watson and Marlow Co., model MHRK 55, Falmouth, UK). Within the cage a stainless steel tubular harness and Teflon jacket (Alice King Chatam Medical Arts, Los Angeles, Calif., USA) prevented the monkey from removing the catheter.

Inside each cage was a $15.4 \mathrm{~cm}^{2}$ stimulus panel mounted on a wall within the monkey's reach. Across the top of the panel were three plastic-covered circles that could be illuminated with a $5 \mathrm{~W}$ bulb. The outer two circles contained red bulbs, and the center circle contained a green bulb. Below each red light was a response lever (Model 121-07; BRS-LVE, Beltsville, Md., USA). The left lever and light were inactive in this study. Responses on the right lever were recorded on an IBM PCjr computer located in the adjacent room.

\section{Procedure}

Each 130-min session consisted of four 25-min, or 20 injection components, during which time drug was available. The components were separated by a 10-min time-out period during which time no lights were illuminated and responding had no programmed consequences. Illumination of the rightmost red light indicated drug availability, during which time 30 responses on the right lever resulted in an infusion of drug and the illumination of the green light. Drug infusion was followed by a 45 -s time-out before the red light was again illuminated and the next infusion was available (FR 30, TO 45).

The four components of a session were distinguished by the duration of the drug infusion in each one. The infusions were 0.5 , $1.7,5.0$, and $16.7 \mathrm{~s}$ in duration, yielding half-log increments in the dose/injection of the drug being used to maintain responding. The doses of cocaine and nomifensine corresponding to these infusion durations were $0.001,0.003,0.01$, and $0.03 \mathrm{mg} / \mathrm{kg}$ per injection. The doses of alfentanil were $0.00003,0.0001,0.0003$, and $0.001 \mathrm{mg} / \mathrm{kg}$ per injection. The order of dose presentation was varied randomly among four orders throughout the study (including ethanol pretreatment conditions). The orders were ascending dose, descending dose, and two mixed dose orders. For short-acting drugs such as cocaine and alfentanil, dose order has not been found to affect the rates of responding maintained by each dose (Winger et al. 1989). This schedule allowed dose-response curves for the drugs to be obtained in each session.

Throughout the procedure, saline was substituted for cocaine or alfentanil approximately every fourth session. If saline-maintained rates of responding were greater than 0.5 response/s in any of the four schedule components, saline continued to be substituted until rates fell below this level. In these experienced monkeys, substitution of saline usually produced a rapid decrease in response rates during a single component. In addition to specified levels of saline responding, specified patterns of drug-maintained responding were necessary in order for ethanol pretreatments or nomifensine substitutions to be made. These criteria were that responding be dose-related, with lowest response rates occurring at small doses and highest rates occurring at large doses, and that the maximum response rate be greater than one response per second. Again, in these well-trained subjects, it was unusual for cocaine or alfentanil not to meet these criteria.

Nomifensine was substituted for cocaine in each of the four monkeys during single sessions. The monkeys were returned to cocaine or saline on the session following nomifensine substitution. Nomifensine was substituted no more frequently than once every fourth session. Pretreatments of 100, 320, 1000, or $1780 \mathrm{mg} / \mathrm{kg}$ ethanol $(15 \% \mathrm{w} / \mathrm{v})$ were given intravenously $10 \mathrm{~min}$ before sessions in which delivery of nomifensine, cocaine or alfentanil was response-contingent. For each drug, a given dose of ethanol was tested at least once but not more than four times in each animal. No particular decision rule was used to determine if ethanol was given more than once. When a pretreatment dose was 
given more than once, the data for all pretreatments with that dose were averaged for each monkey. This average was then added to the average or single observation data from each of the other three monkeys, and the total divided by four to constitute the data shown in the figures. For cocaine and alfentanil, data from the sessions immediately preceding each ethanol pretreatment were averaged to obtain the control values for each drug. The number of sessions making up the control values is indicated in Figs 2 and 3 as " $n$ ".

\section{Drugs}

Alfentanil was provided by Janssen Pharmaceuticals (Beerse, Belgium); cocaine hydrochloride was purchased from Mallinckrodt (St Louis, Mo., USA); and nomifensine was obtained from Hoechst-Roussel Pharmaceuticals (Somerville, N.J., USA).

Ethanol was manufactured by McCormick Distilling Co. (Weston, Mo., USA).

\section{Statistical analysis}

Results were analyzed using an analysis of variance (ANOVA), and a least squares means table was generated to compare baseline data points to each of the pretreatment data points. The level of significance was $P<0.05$.

\section{Results}

There was a dose-related increase in the rate of self-administration for each of the three drugs, but the effects of ethanol pretreatments on self-administration differed among the drugs. Figure 1 illustrates the average results of various doses of ethanol pretreatments on self-administration of each of the three drugs. There was considerable variability among animals under conditions of cocaine self-administration, with the most consistent increases in cocaine self-administration produced by $1000 \mathrm{mg} / \mathrm{kg}$ ethanol (top panel). For nomifensine (middle panel), $1000 \mathrm{mg} / \mathrm{kg}$ ethanol again produced the greatest increase in self-administration. Finally, none of the ethanol pretreatment doses had an effect on responding maintained by alfentanil (bottom panel).

The interaction between the most effective dose of ethanol $(1000 \mathrm{mg} / \mathrm{kg})$ and cocaine is shown in detail for the four individual monkeys in Fig. 2. The bottom panel shows the data averaged across four monkeys. Only one monkey, RC245, failed to show an increase in the rate of self-administration for any dose of cocaine following pretreatment with $1000 \mathrm{mg} / \mathrm{kg}$ ethanol. There was no clear ethanol-induced stimulation on any of the occasions that ethanol was administered to this monkey. Monkey J30 had an increase in cocaine-maintained responding at a dose of $0.03 \mathrm{mg} / \mathrm{kg}$ per injection after receiving ethanol, which was the only dose of cocaine that maintained rates higher than saline in this monkey. An increase in rates of responding maintained by cocaine following $1000 \mathrm{mg} / \mathrm{kg}$ ethanol could be seen over a larger range of doses in the two remaining monkeys. Monkey $671 \mathrm{P}$ had higher response rates after ethanol pretreatment across the two largest doses tested, and RC177 had increased rates at the three largest doses of cocaine
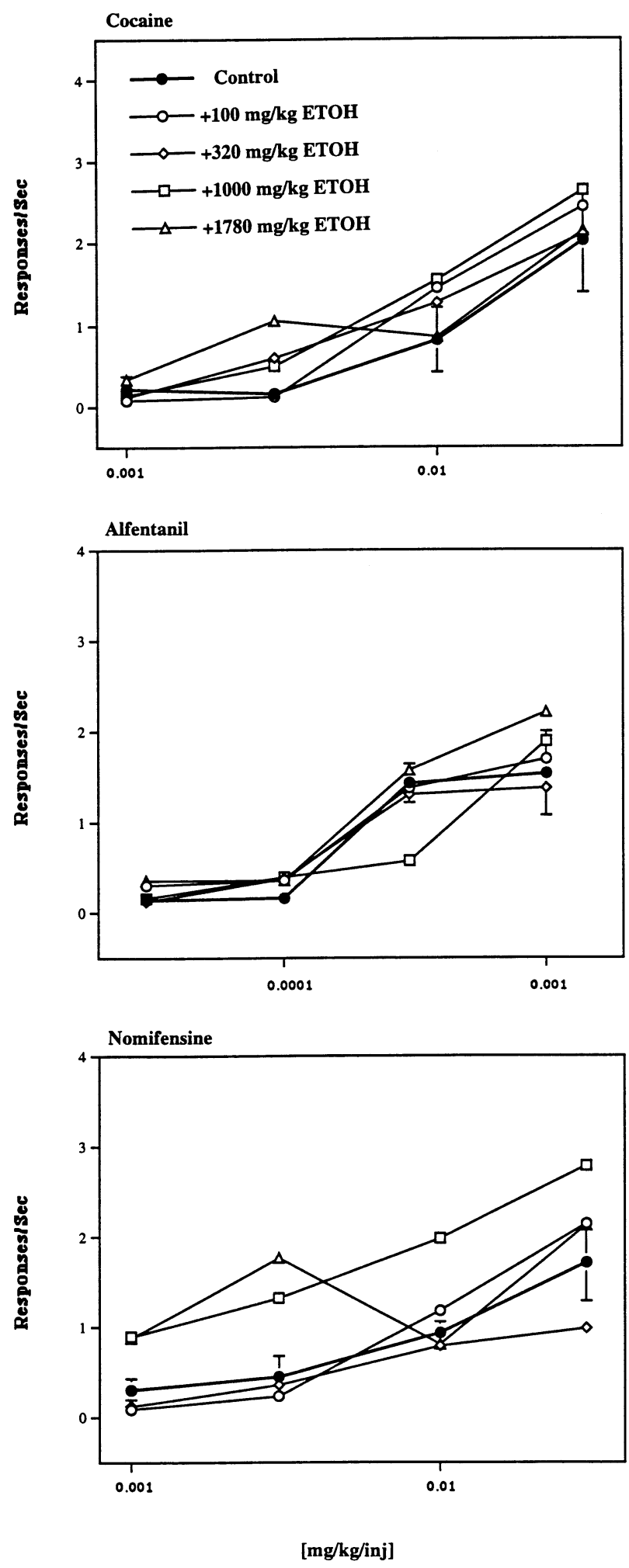

Fig. 1 Average response rates maintained by responding for cocaine (upper panel), nomifensine (middle panel), or alfentanil (lower panel) for four monkeys following ethanol administration. Closed circles represent responding for each drug in the absence of ethanol. Vertical bars around these points represent \pm 1 SEM. The four different ethanol doses were: $100 \mathrm{mg} / \mathrm{kg}$ (open diamonds), $320 \mathrm{mg} / \mathrm{kg}$ (open squares), $1000 \mathrm{mg} / \mathrm{kg}$ (open circles), and $1780 \mathrm{mg} / \mathrm{kg}$ (open inverted triangles). Vertical lines represent the standard error of the control response rates 
Fig. 2 Response rates maintained by cocaine following pretreatment with $1000 \mathrm{mg} / \mathrm{kg}$ ethanol. Closed circles represent control rates of responding for cocaine, and open squares represent response rates for cocaine following administration of $1000 \mathrm{mg} / \mathrm{kg}$ ethanol. The top four panels represent data from individual monkeys; $n$ indicates the number of observations for the indicated dose-response curve. The vertical bars represent \pm 1 SEM. When $n>2$ and no vertical bars are apparent, the variability is within the data point. The lower panel represents the average data $( \pm 1$ SEM) for the four monkeys

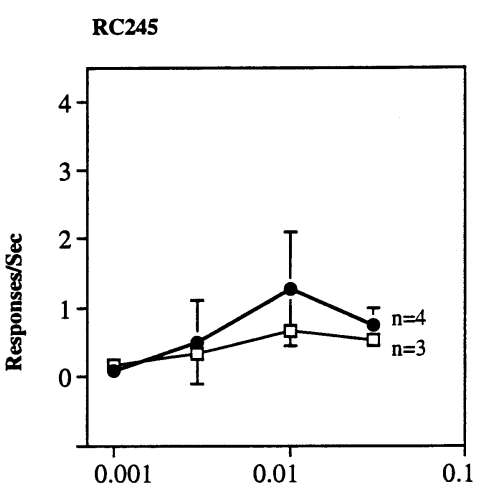

J30

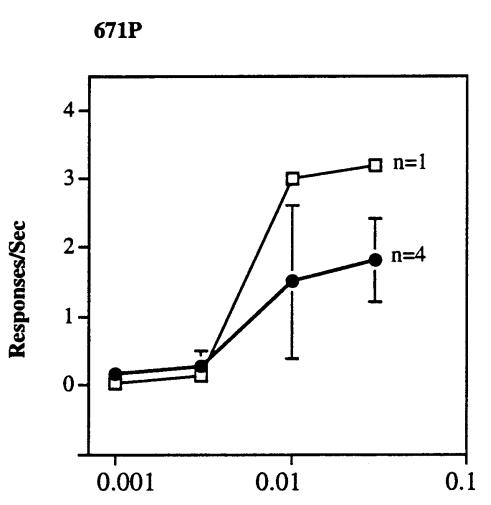

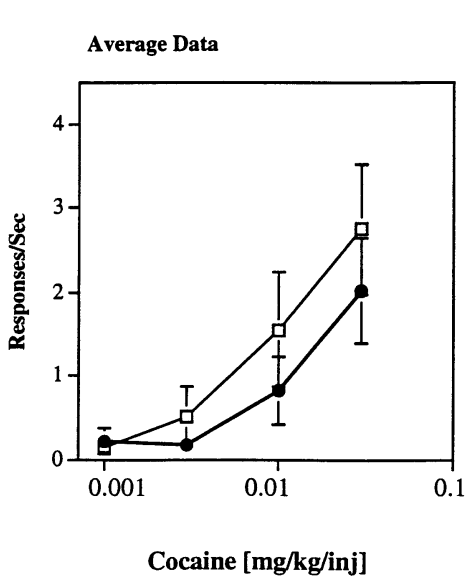

following administration of $1000 \mathrm{mg} / \mathrm{kg}$ ethanol. The average data show a slight, but not statistically significant, increase in rate of responding for three highest doses of cocaine after $1000 \mathrm{mg} / \mathrm{kg}$ ethanol $[F(4,98)=0.29$, ns].

Overall, the $1000 \mathrm{mg} / \mathrm{kg}$ dose of ethanol had a more marked effect on rate of responding maintained by nomifensine than on that maintained by cocaine, as can be seen in Fig. 3, and this interaction proved to be statistically significant $[F(4,98)=5.09, P<0.001]$. However, the same two monkeys (671P and RC177) that were stimulated by ethanol under the cocaine condition were most affected by ethanol under the nomifensine condition. Rates of nomifensine-maintained responding in the remaining two animals were only slightly modified by ethanol.

\section{Discussion}

The data are consistent in demonstrating that, in this experimental paradigm, ethanol pretreatments do not increase the potency of cocaine as a reinforcer through the production of cocaethylene. Had this been the case, the potency of cocaine alone would have been increased following ethanol pretreatments. The fact that there was no significant increase in cocaine's potency in the presence of ethanol suggests that cocaethylene played no role in augmenting cocaine's reinforcing potency. However, two monkeys did demonstrate an increased rate of cocainemaintained responding following ethanol pretreatment, and an argument could be made that cocaethylene production may differ among animals. This argument is re- 
Fig. 3 Response rates maintained by nomifensine following pretreatment with $1000 \mathrm{mg} / \mathrm{kg}$ ethanol. Closed circles represent control rates of responding for nomifensine, and open squares represent response rates for nomifensine following administration of $1000 \mathrm{mg} / \mathrm{kg}$ ethanol. The top four panels represent data from individual monkeys. The lower panel represents the average data for the four monkeys. Other symbols are as in Fig. 2

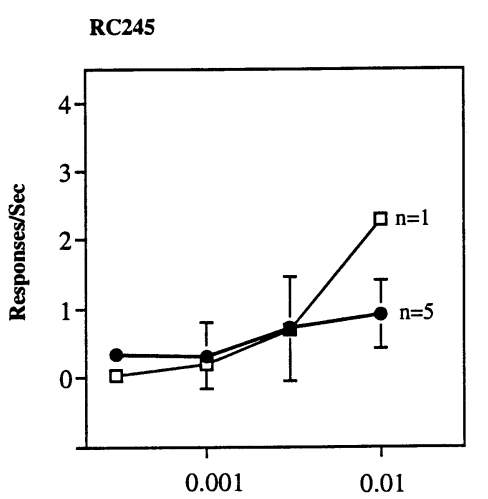

671P

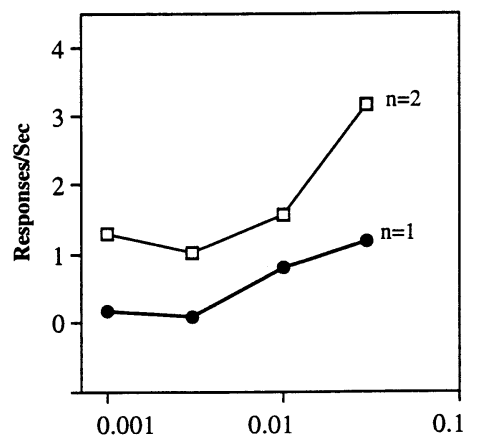

J30

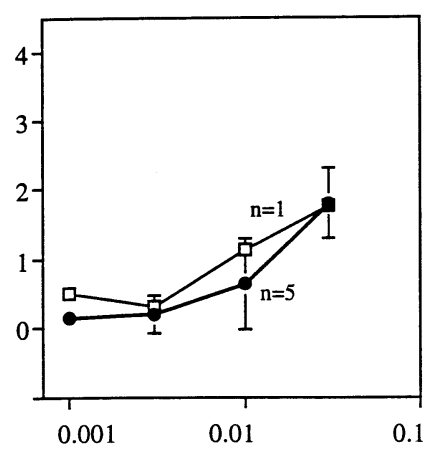

RC177

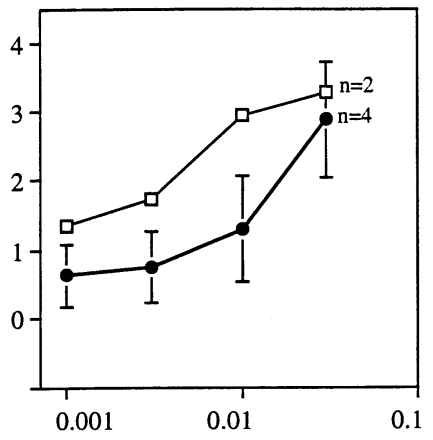

Average Data

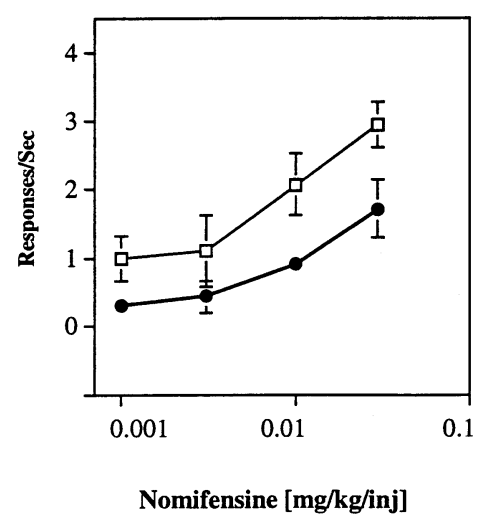

$\longrightarrow$ Nomifensine Control $\longrightarrow+1000 \mathrm{mg} / \mathrm{kg}$ ETOH

jected by the finding that these same two monkeys also showed increased rates of nomifensine-maintained responding, a situation in which cocaethylene could not have been a factor. Rather, the data indicate that there are individual differences among animals in the likelihood of stimulation following ethanol administration.

The stimulant effects of ethanol on operant responding have been observed in other situations as well. Ethanol doses similar to those used in the present study (1000-2000 mg/kg) have been shown to increase rates of responding maintained by food in squirrel monkeys (Barrett 1976). However, the complete absence of an effect of ethanol on alfentanil-maintained responding, as well as individual differences in this effect, suggests that a general ethanol-induced stimulation of behavior did not occur.
None of the monkeys self-administering alfentanil showed any stimulation or suppression by ethanol. This raises two possibilities for ethanol's stimulating effects that cannot be separated by these studies. Either few monkeys (in this case, two of seven) demonstrate stimulant effects of ethanol; or the percentage showing this effect is higher (two of four) but only when a central stimulant is serving as a reinforcing event. There is a precedent for reinforcer-selective stimulant effects of ethanol. Barrett (1976) demonstrated that ethanol's effects were quite different depending on the nature of the event maintaining behavior. Food-maintained response rates were increased and shock-maintained response rates were decreased by the same dose of ethanol. The two classes of reinforcers in this experiment (CNS stimulants and an opioid drug) do seem as different as reinforcers as 
do food and shock, but the mechanism underlying the individual differences observed here, whether behavioral, historical, or pharmacological, remains unknown. Certainly, evaluating the effects of ethanol in a large number of subjects would help to delineate the nature of the individual differences.

The role of cocaethylene in the enhancement of cocaine's behavioral effects when combined with ethanol remains unclear (Fowler et al. 1992; Jatlow 1993). These data do not detract from the possibility that concurrent abuse of cocaine and ethanol in humans is due to the formation of cocaethylene. Since ethanol was given noncontingently in these studies, its administration did not mimic that of human drug abusers. People who combine use of cocaine with ethanol presumably do so in a pattern that maximizes cocaethylene formation, if this compound is, in fact, important to the maintenance of this form of polydrug abuse. Under the current experimental protocol, it is not certain that there was sufficient time for cocaethylene to be formed, or whether any production of cocaethylene occurred in a sufficiently responsecontingent way to modify the reinforcing effects of cocaine. The procedure is sensitive to pretreatments that increase the potency of the reinforcing drug, since administration of the MAO-B inhibitor $l$-deprenyl produced a marked leftward shift in the reinforcing effects of beta phenylethylamine in an identical procedure (Winger, unpublished observations).

Further studies in which cocaethylene formation is measured, as well as protocols in which ethanol as well as cocaine are available on a response-contingent basis, might help to clarify these issues. However, the current data indicate that in future experiments, the choice of drugs used to control for the effects of cocaine may be critical, as well as individual differences in responsiveness to ethanol. Although we remain ignorant of the mechanism whereby ethanol produced stimulation of behavior maintained by a dopamine reuptake blocker other than cocaine, but had no effect on behavior maintained by an opioid, it seems clear that there is an important difference in ethanol's ability to modify behavior controlled by drugs with different mechanisms of action. This difference may be reflected in populations of human addicts, where cocaine addicts are twice as likely as opioid addicts to abuse alcohol (Rounsaville et al. 1991). Further studies of the differential effects of ethanol on drugs of abuse may be important to the understanding of various forms of polydrug abuse.

\section{References}

Bailey DN (1993) Plasma cocaethylene concentrations in patients treated in the emergency room or trauma unit. Am J Clin Pathol 99: 123-127

Barrett JE (1976) The effects of alcohol, chlordiazepoxide, cocaine and pentobarbital on responding maintained under fixedinterval schedules of shock or food presentation. J Pharmacol Exp Ther 196: 605-615

Fowler JS, Volkow ND, Logan J, MacGregor RR, Wang GJ, Wolf AP (1992) Alcohol intoxication does not change $\left[{ }^{11} \mathrm{C}\right]$ cocaine pharmacokinetics in human brain and heart. Synapse 12: 228-235

Grant BF, Harford TC (1990) Concurrent and simultaneous use of alcohol with cocaine: results of national survey. Drug Alcohol Depend 25: 97-104

Jatlow P (1993) Cocaethylene: pharmacologic activity and clinical significance. Ther Drug Monit 15: 533-536

Jatlow P, Elsworth JD, Bradberry CW, Winger G, Taylor JR, Russell R, Roth RH (1991) Cocaethylene: a neuropharmacologically active metabolite associated with concurrent cocaine-ethanol ingestion. Life Sci 48: 1787-1794

Katz JL, Terry P, Witkin JM (1992) Comparative behavioral pharmacology and toxicology of cocaine and its ethanol-derived metabolite, cocaine ethyl-ester (cocaethylene). Life Sci 50: $1351-1361$

McCance-Katz EF, Price LH, McDougle CJ, Kosten TR, Black JE, Jatlow PI (1993) Concurrent cocaine-ethanol ingestion in humans: pharmacology, physiology, behavior, and the role of cocaethylene. Psychopharmacology 111: 39-46

Rafla FK, Epstein RL (1979) Identification of cocaine and its metabolites in human urine in the presence of ethyl alcohol. J Anal Toxicol 3: 59-63

Rousanville BJ, Anton SF, Carroll K (1991) Psychiatric diagnoses of treatment-seeking cocaine abusers. Arch Gen Psychiatry 48: 43-51

Siegel RK (1984) Changing patterns of cocaine use: longitudinal observations, consequences, and treatment. NIDA Res Monogr 50: $92-110$

Smith RM (1984) Ethyl esters of arylhydroxy- and arylhydroxymethoxycocaines in the urines of simultaneous cocaine and ethanol users. J Anal Toxicol 8: 38-42

Weiss RD, Mirin SM, Griffin ML, Michael JL (1988) Psychopathology in cocaine abusers. J Nerv Ment Dis 176[12]: 719-725

Winger G (1994) Dopamine antagonist effects on behavior maintained by cocaine and alfentanil in rhesus monkeys. Behav Pharmacol 5: 141-152

Winger G, Woods JH (1985) Comparison of fixed-ratio and progressive- ratio schedules of maintenance of stimulant drug-reinforced responding. Drug Alcohol Depend 15: 123-130

Winger G, Palmer RK, Woods JH (1989) Drug-reinforced responding: rapid determination of dose-response functions. Drug Alcohol Depend 24: 135-142

Woodward JJ, Mansbach R, Carroll FI, Balster RL (1991) Cocaethylene inhibits dopamine uptake and produces cocaine-like actions in drug discrimination studies. Eur J Pharmacol 197: 235-236 